\title{
Nutritional depletion of total mixed rations by European starlings: Projected effects on dairy cow performance and potential intervention strategies to mitigate damage
}

\author{
J. C. Carlson, ${ }^{* 1}$ R. S. Stahl, ${ }^{*}$ S. T. DeLiberto, ${ }^{*}$ J. J. Wagner,† T. E. Engle,† R. M. Engeman, ${ }^{*}$ C. S. Olson, $\ddagger$ \\ J. W. Ellis, ${ }^{*}$ and S. J. Werner* \\ *Wildlife Services, National Wildlife Research Center, USDA-Animal and Plant Health Inspection Service, 4101 LaPorte Avenue, Fort Collins, \\ CO 80521 \\ †College of Agricultural Sciences, Department of Animal Science, and \\ $\ddagger$ Warner College of Natural Resources, Department of Fish, Wildlife and Conservation Biology, Colorado State University, \\ Fort Collins 80523-1474
}

\section{ABSTRACT}

European starlings are an invasive bird species in North America that are known to cause damage to commercial dairies through the consumption of total mixed rations (TMR) destined for dairy cows. We hypothesized that large foraging flocks of starlings alter the physical composition of TMR, and that this change may be significant enough to affect milk production. To better determine if production losses could potentially occur in commercial dairies as a consequence of feed consumption by foraging flocks of starlings, we conducted controlled feeding experiments using a TMR sourced from a commercial dairy that is chronically plagued with seasonal starling damage. European starlings selected the high-energy fraction of the TMR and reduced starch and crude fat availability. Using the dairy National Research Council production model equations, the nutritional changes measured in the controlled feeding experiments could potentially reduce the productivity of dairies. Model output suggests that for Holsteins producing $32 \mathrm{~kg}$ of milk/d, total required net energy intake $\left(\mathrm{NE}_{\mathrm{I}}\right)$ was $31.5 \mathrm{Mcal} / \mathrm{d}$. Within the reference TMR, $\mathrm{NE}_{\mathrm{I}}$ supplied was $29.3 \mathrm{Mcal} / \mathrm{d}$, whereas within the starling-consumed TMR $\mathrm{NE}_{\mathrm{I}}$ supplied was $27.7 \mathrm{Mcal} / \mathrm{d}$. Following our nutrition experiments, we assessed the efficacy of pelleted feed as a deterrent strategy for bird damage management in commercial dairies. Six different pelleted feed treatments of differing diameter were offered to starlings. All pellets of $0.95 \mathrm{~cm}$ diameter or larger inhibited starling consumption by $\geq 79 \%$.

Key words: dairy production, bird damage management, nutrition

Received March 10, 2017.

Accepted October 5, 2017.

${ }^{1}$ Corresponding author: james.c.carlson@aphis.usda.gov

\section{INTRODUCTION}

European starlings (Sturnus vulgaris) are native to Eurasia and North Africa and have successfully established populations on each continent except Antarctica (Feare, 1984; Linz et al., 2007; Rollins et al., 2009). Starlings seasonally congregate in large roosting groups and exploit the abundant and nutritious food sources found on concentrated animal feeding operations (Besser et al., 1968; Dolbeer et al., 1978; LeJeune et al., 2008). Starlings have been documented consuming livestock feed in animal agricultural operations in the United States, Europe, and Australia (Feare et al., 1992; Bentz et al., 2007; Carlson et al., 2011).

Livestock feed consumption by starlings appears to cause economically significant damage to feedlots and dairies in the United States (Glahn and Otis, 1981; Twedt and Glahn, 1982). Estimates of bird damage in commercial dairies within Wisconsin, New York, and Pennsylvania suggest that starling damage resulted in $\$ 64,000$ of feed loss annually within dairies experiencing 10,000 or more birds per day, and feed costs per cwt increased $42 \%$ in dairies with 10,000 or more birds (Shwiff et al., 2012).

Feed consumption by starlings may negatively affect animal performance. Wright (1973) and Feare and Swannack (1978) found increased weight gain in cattle when fed in bird-excluded areas. Feare (1984) suggested that if feed consumption by birds occurs at the bunk, then removal of high-energy feed ingredients by starlings may reduce animal performance, and these losses may be economically significant to producers. Depenbusch et al. (2011) provided nutritional comparisons of cattle rations before and after starling damage and concluded these changes could potentially decrease growth rates and feed conversion efficiency of feeder cattle. The producer survey conducted by Shwiff et al. (2012) did not reveal differences in milk production between dairies experiencing and not experiencing bird damage. 
To better determine if production losses could potentially occur in commercial dairies as a consequence of feed consumption by foraging flocks of starlings, we conducted controlled feeding experiments using a TMR sourced from a commercial dairy that is chronically plagued with seasonal starling damage. The objectives of these experiments were to (1) estimate the nutritional offsets caused by starling consumption of a TMR; (2) predict the effect on dairy cow performance caused by starling consumption of TMR using the dairy NRC (2001) production model equations; and (3) identify if particle size influences starling consumption of dairy TMR.

\section{MATERIALS AND METHODS}

We partnered with a commercial dairy in northern Colorado to conduct these experiments. During the winter of 2011 to 2012, we observed that this commercial dairy experienced approximately 5,000 to 15,000 starlings per day between November 15 and March 31. The dairy had a herd size of 2,767 cows, and 1,403 of these cows were in production. The herd consisted of $80 \%$ Holstein and 20\% Holstein $\times$ Jersey cross. Milk cows on average were 43 mo old, weighed $589 \mathrm{~kg}$, and were approximately 200 DIM. Bulk tank milk contained $3.48 \%$ milk fat and $3.02 \%$ milk protein. Feed intake and milk production data for late-lactation cattle (DIM $\geq 160)$ were used in these analyses. Feed intake for late-lactation cattle was approximately $25.5 \mathrm{~kg}$ (dry weight)/head per day. Milk production per head per day for late-lactation cattle was approximately 31.75 $\mathrm{kg}$.

Starlings were live trapped from the commercial dairy using mist nets and modified Australian crow traps. All starlings were transported to the United States Department of Agriculture, National Wildlife Research Center (NWRC) in Fort Collins, Colorado, for feeding experiments. Nutrition experiments were conducted in 2012 and particle size testing was conducted in 2016. All starlings were quarantined for 2 wk with ad libitum access to feed (Layena poultry pellets, Purina Animal Nutrition LLC, St. Louis, MO) and water. Starlings were maintained in their quarantine cages until the pretest period of the experiment $(4.9 \times 2.4 \times 2.4 \mathrm{~m}$, length $\times$ width $\times$ height, respectively).

\section{European Starling Feeding Experiments: Estimating Nutritional Offsets Caused by European Starlings}

On February 29, 2012, starlings $(\mathrm{n}=55)$ were moved from quarantine and housed 5 birds per $3.05 \times 3.05 \times$ $2.4 \mathrm{~m}$ (length $\times$ width $\times$ height, respectively) cages for the pretest and test. Birds used on test were selected arbitrarily from quarantined starlings. If a bird was injured or appeared sick it was excluded from the nutrition experiment. The pretest lasted $5 \mathrm{~d}$. During pretest, birds within each cage were fed $1 \mathrm{~kg}$ (as fed) of the TMR test diet daily. The TMR offered was a late-lactation ration fed to milk producing cows (DIM $\geq 160$ ). The TMR offered during pretest was also used for the nutrition experiment.

The nutrition experiment was conducted from March 5 to 8, 2012. Starting March 5, a total of $15 \mathrm{~kg}$ of premixed, late-lactation TMR (as fed) was collected directly from feed trucks at $0600 \mathrm{~h}$ and brought to NWRC-Fort Collins for nutritional testing. Fresh TMR was offered daily within each of 10 cages $(\mathrm{n}=10 ; 5$ starlings per cage). For 4 consecutive days, $1.1 \mathrm{~kg}$ of feed, as fed, was weighed out for each cage. A total of $1 \mathrm{~kg}$ was offered to starlings within an aluminum tray $(0.9 \times 0.6 \times 2.54 \mathrm{~cm}$, length $\times$ width $\times$ diameter, respectively) and the remaining $100 \mathrm{~g}$ were used as a reference sample. This process of subsampling was used to ensure that the reference ration was representative of the feed offered to starlings in each respective cage. The reference sample was placed outside each respective cage in a paper bag. Both reference and starling-consumed rations were identified by cage number and day. An additional 1-kg TMR sample, as fed, was placed in a cage absent of starlings to estimate daily feed desiccation (e.g., evaporative water loss). Following $24 \mathrm{~h}$ of starling foraging, the starling-consumed and desiccation samples were weighed. The starling-consumed and reference samples were then placed in a drying oven at $75^{\circ} \mathrm{C}$ for $24 \mathrm{~h}$. After drying was complete, all samples were ground using a Model 4, Thomas Wiley mill (Thomas Scientific, Swedesboro, NJ). The Wiley mill was opened and brushed clean after processing each individual sample to eliminate cross contamination. Ground samples were stored in a walk-in cooler, set to $4^{\circ} \mathrm{C}$, until all samples were processed and ready to ship to a laboratory for nutritional analysis.

For the purpose of assessing component selection, 1 additional cage of group-housed starlings (5 starlings) was provided TMR separated into the 7 ration components (i.e., 7 bowls, each containing $100 \mathrm{~g}$ of individual ration components). This assessment was not replicated; it was conducted to better identify what feed components were likely being consumed to cause the measured changes between rations exposed to starlings and reference TMR formulations. The feed offered consisted of the high-energy components within the TMR: steamed-flaked corn (SFC), Propel energy nugget (EN; Nestle Purina, St. Louis, MO), corn gluten (CG), dry distillers grains (DDG), canola meal (CM), corn 
silage (CS), and mineral supplement. The component assessment was conducted for $4 \mathrm{~d}$. An additional cage absent of starlings contained $100 \mathrm{~g}$ of each component for estimates of daily feed desiccation. On each of test d 1 and 2, we offered the 5 group-housed starlings all 7 components. On each of test d 3 and 4, we offered the same starlings TMR separated into 6 ration components (i.e., 6 bowls, each containing $100 \mathrm{~g}$ of individual ration components). This second assessment deliberately excluded the most favored feed item observed during test d 1 and 2 (i.e., EN). Percent consumed was measured for each component using the equation consumption $=$ $[1-($ treatment/desiccation $)] \times 100$. Treatment refers to the grams of feed remaining after exposure to birds and desiccation refers to the grams of feed remaining after exposure to air. Estimates of feed consumption were averaged between days for each of the 2 selection tests and reported as percent consumed.

\section{Testing Pellet Size as a Deterrent to Livestock Feed Depredation by European Starlings}

On April 6, 2016, starlings $(\mathrm{n}=132)$ were removed from quarantine and housed 2 birds per $1.83 \times 0.914 \times$ $0.914 \mathrm{~m}$ (length $\times$ width $\times$ height, respectively) cage for pretest and particle size testing. Pretest lasted 5 d. During the pretest, all cages were offered $150 \mathrm{~g}$ of a nutritionally complete poultry layer pellet of 0.396 $\mathrm{cm}$ in diameter (Ranch-Way Feeds, Fort Collins, CO). Starting April 11, 2016, the layer pellet offered to starlings was collected and weighed. Weighback occurred for $3 \mathrm{~d}$. We ranked birds based upon their 3 -d average consumption of pretest pellets and then cages were assigned to 1 of 6 test pellets $(2.22,1.91,1.27,0.953,0.553$, or $0.396 \mathrm{~cm}$ in diameter). Treatment assignments were stratified based upon ranked consumption data such that treatment groups were similarly populated with high and low consumers. The pellets were all produced by Ranch-Way Feeds using the same nutritionally complete poultry layer feed offered to birds during pretreatment. Starting April 14, we offered starlings $150 \mathrm{~g}$ of the test diet consisting of 1 of the 6 different pellet diameters ( $\mathrm{n}=11$ cages per treatment). An additional cage housed desiccation samples of feed for each of the 6 treatments. The following day the remaining feed was collected and weighed. The response variable is pellet consumption per cage and it was measured in grams of feed consumed using the equation consumption per cage $=($ desiccation - treatment $)$.

At the completion of all European starling feeding experiments, captured starlings were euthanized following methods conforming to agency policy as stated in USDA/APHIS/WS Directive 2.505 (USDA APHIS,
2011) and approved by the NWRC Internal Animal Care and Use Committee (QA-1742, J. C. Carlson, study director).

\section{Data Analysis}

Nutritional Analysis. Nutritional testing of dairy TMR samples were conducted at Cumberland Valley Analytical Services (Hagerstown, MD) using nearinfrared reflectance spectroscopy and wet-chemistry analyses. Near-infrared reflectance spectroscopy was used to estimate DM, moisture as a percentage of asfed CP, calcium, phosphorus, magnesium, ADF, NDF, starch, crude fat (CF), ash, sodium, TDN, $\mathrm{NE}_{\mathrm{L}}$ (mcal/ $\mathrm{kg}), \mathrm{NE}_{\mathrm{M}}(\mathrm{mcal} / \mathrm{kg}), \mathrm{NE}_{\mathrm{G}}(\mathrm{mcal} / \mathrm{kg})$, and $\mathrm{NFC}$ on a DM basis. Wet chemistry was used to determine calcium, phosphorus, magnesium, potassium, iron (mg/ $\mathrm{kg})$, zinc $(\mathrm{mg} / \mathrm{kg})$, and copper $(\mathrm{mg} / \mathrm{kg})$ content.

Statistical Analysis. All nutritional and particle size data were analyzed using ANOVA within mixed linear models (Proc Mixed, SAS 9.2, SAS Institute Inc., Cary, NC). For the nutrition data, fixed effects included treatment status (starling consumed and reference rations) and cage was included as a random effect. For the particle size data, fixed effects included treatment group (the 6 particle sizes) and cage was included as a random effect. For both analyses, denominator degrees of freedom were calculated using the Satterthwaite approximation.

Nutrition data were compared for starling consumed and reference rations. A total of 22 univariable models $(m=22)$ were created, 1 model for each of the nutritional variables reported by Cumberland Valley Analytical Services. Because multiple hypotheses were tested, we controlled for false discoveries using the Benjamini-Hochberg procedure (Benjamini and Hochberg 1995). For all analyses, the false discovery rate was set at $\alpha=0.05$. Univariable analyses were ranked by $P$-value from smallest $(1)$ to largest $(m)$. Cutoff values for the rejection of null hypotheses were calculated as $(\mathrm{rank} / m) \times \alpha$ (Table 1$)$.

Starling consumption of the 7 TMR components is reported as percent consumed with standard deviations. To estimate grams of TMR consumed by cage and by bird, we assumed the difference in grams of TMR recovered within the rations exposed to starlings and the desiccation rations reflect TMR consumed by starlings. This difference was then divided by the number of birds within each cage (5) for the estimation of per-bird consumption, calculated as TMR consumption $=($ desiccation - treatment $) / 5$.

NRC Dairy Production Modeling. Parameterization of the NRC (2001) dairy production model was 
Table 1. Analysis of TMR nutrition data for reference and rations exposed to starlings

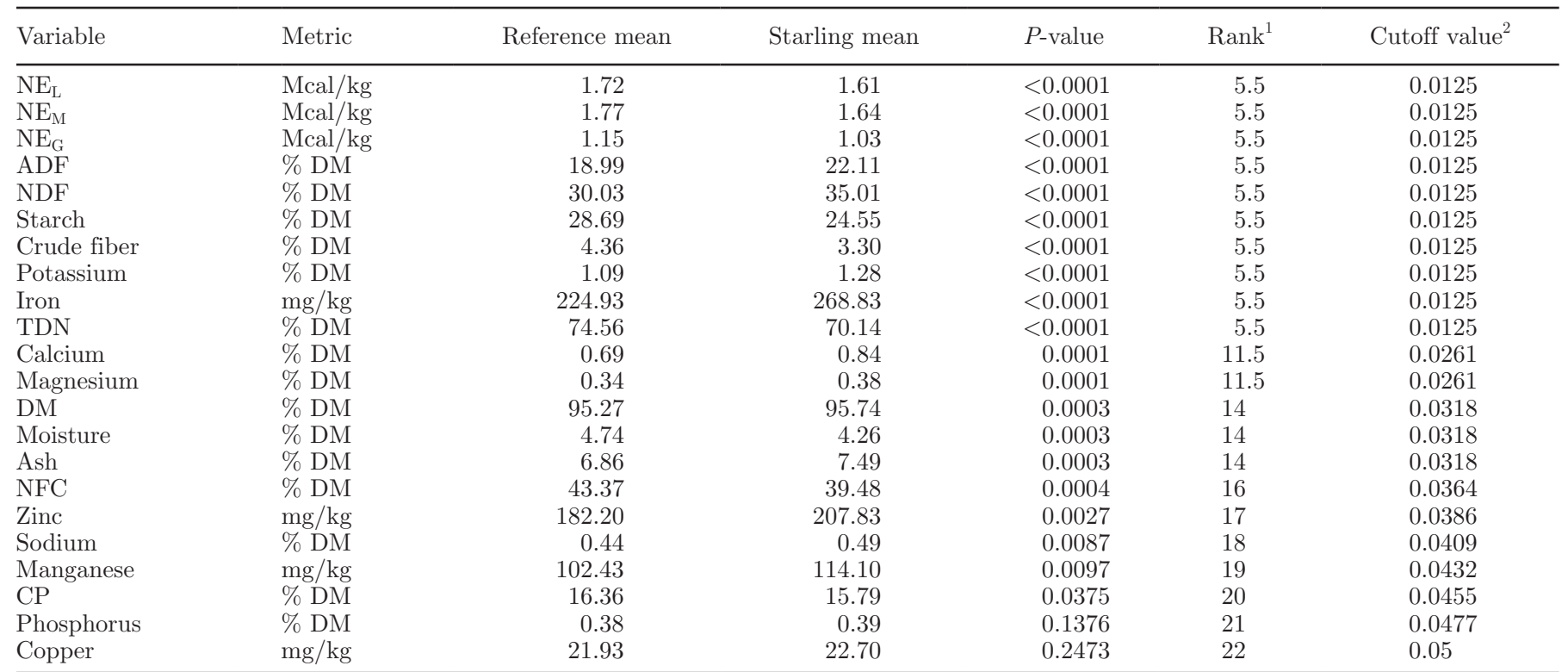

${ }^{1}$ Rank order of $P$-values from nutrient analyses of cattle feed samples.

${ }^{2}$ Benjamini-Hochberg cutoff values for rejection of null hypotheses.

based upon animal condition and feed formulation data provided by the commercial dairy and the nutrition experimental data. We rebalanced the ration based upon the fractional difference in $\mathrm{CF}$ concentrations between the rations exposed to starlings and the reference ration. To rebalance the rations exposed to starlings, we assumed the nutritional changes were influenced by starlings selectively consuming the 2 most preferred components (EN and EFC).

Using the known change in $\mathrm{CF}$ between reference and rations exposed to starlings, we estimated the amount of SFC and EN remaining following starling consumption using the linear equation

$$
\begin{gathered}
{ }_{0} \mathrm{CF}_{\mathrm{TMR}}=\mathrm{X} \times\left(\% \mathrm{CF}_{\mathrm{SFC}}+\% \mathrm{CF}_{\mathrm{EN}}\right) \\
+\Sigma \% \mathrm{CF} \text { for all other TMR components, }
\end{gathered}
$$

where $\mathrm{X}=$ change in percent of $\mathrm{CF}$ attributed to starling consumption of $\mathrm{EN}$ and $\mathrm{SFC} ; \mathrm{CF}_{\mathrm{SFC}}$ is percent of $\mathrm{CF}$ within the SFC component; and $\% \mathrm{CF}_{\mathrm{EN}}$ is the percent of $\mathrm{CF}$ within the EN component. All other components were assumed to be unaffected by bird feeding and set to the relative mass distribution of the remaining feed components. To estimate the effect of starling foraging on feed formulation, the mass percent of the remaining components was increased by a constant scalar so that the resulting feed composition summed to $100 \%$. The dry mass and wet mass for each feed component were calculated from these consumption-corrected distribu- tions. These corrected feed component values were then used to parameterize the NRC dairy production model for rations exposed to starlings (Table 2).

\section{RESULTS}

\section{Component Selection by European Starlings}

Within the starling cage used to assess TMR component selection, the birds primarily selected EN among the 7 components offered (Figure 1). Within the percent consumed graph, the 5 group-housed starlings consumed, on average, $21.5 \pm 3.79 \mathrm{~g}( \pm \mathrm{SD})$ of TMR/ bird per day, and $49.2 \%$ of their total diet consisted of EN. In the second assessment of TMR component selection, excluding EN, component selection and percent consumed by starlings changed considerably, where the 5 group-housed birds primarily selected SFC and consumed $31.1 \pm 1.41 \mathrm{~g}$ of TMR/bird per day (Figure 2).

\section{Nutritional Analysis}

The nutritional data in Table 1 suggests starling consumption of TMR altered the nutritional characteristics within the ration. Rations exposed to starlings had lower DM concentrations of $\mathrm{NE}_{\mathrm{L}}(P<0.001), \mathrm{NE}_{\mathrm{M}}$ $(P<0.001)$, and $\mathrm{NE}_{\mathrm{G}}(P<0.001)$. Rations exposed to starlings also had lower DM concentrations of starch $(P$ $<0.001)$, CF $(P<0.001)$, TDN $(P<0.001)$, and CP $(P=0.038)$. Rations exposed to starlings had higher 
Table 2. Dairy TMR formulations for reference and rations exposed to starlings

\begin{tabular}{|c|c|c|c|c|c|}
\hline $\begin{array}{l}\text { High-energy } \\
\text { TMR components }\end{array}$ & $\begin{array}{c}\text { Reference wet } \\
\text { weight }(\mathrm{kg} / \mathrm{cow})\end{array}$ & $\% \mathrm{DM}$ & $\begin{array}{c}\text { Reference } \\
\text { DM (kg/cow) }\end{array}$ & $\begin{array}{c}\text { Starling } \\
\mathrm{DM}^{1}(\mathrm{~kg} / \mathrm{cow})\end{array}$ & $\begin{array}{l}\text { Percent } \\
\text { reduction }\end{array}$ \\
\hline Corn silage & 5.26 & 34 & 1.79 & 1.79 & 0 \\
\hline Alfalfa haylage & 2.31 & 30 & 0.69 & 0.69 & 0 \\
\hline Alfalfa hay & 4.38 & 90 & 3.94 & 3.93 & 0 \\
\hline Hominy & 3.40 & 90 & 3.06 & 3.06 & 0 \\
\hline Dry distillers grain & 1.34 & 90 & 1.21 & 1.21 & 0 \\
\hline Energy nugget & 0.45 & 97 & 0.44 & 0.30 & 47.19 \\
\hline Canola meal & 2.81 & 90 & 2.53 & 2.53 & 0 \\
\hline Steam-flaked corn & 2.72 & 90 & 2.45 & 1.70 & 44.50 \\
\hline
\end{tabular}

${ }^{1}$ Starling DM (kg/cow) refers to the amount of DM of feed, measured in kilograms, offered to a single cow per day. Energy nugget (Nestle Purina, St. Louis, MO).

${ }^{2}$ Percent reduction is a measurement of the reduction projected to occur in starling consumed feed relative to the reference rations for each specific component.

DM concentrations of $\operatorname{ADF}(P<0.001), \operatorname{NDF}(P<$ $0.001)$, potassium $(P<0.001)$, and calcium $(P<0.001)$. On average, individual starlings ate $44.43 \pm 2.88 \mathrm{~g}$ of TMR/bird per day. The rations exposed to starlings contain $1.06 \%$ less CF than the reference rations. Using the equation above, we were able to estimate a decrease of $0.14 \mathrm{~kg} /$ cow of EN and a $0.75 \mathrm{~kg} /$ cow of SFC in the TMR. This reduction accounts for a 47.2 and $44.5 \%$ dry mass reduction in the component fraction of the TMR for EN and SFC, respectively (Table 2).

\section{NRC Dairy Production Modeling}

Based upon our NRC (2001) dairy production model estimates, dairy cow performance can be affected as a consequence of starling consumption of the latelactation TMR (Table 3). For Holsteins producing 32

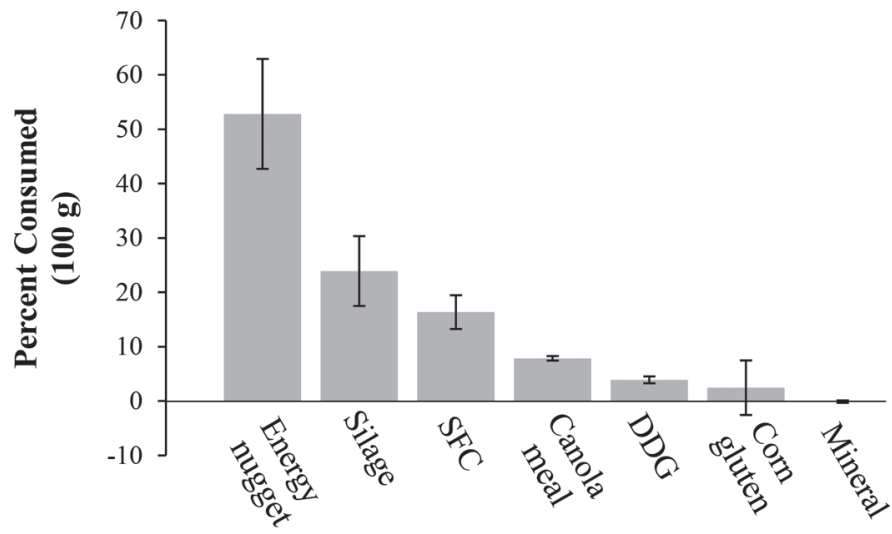

Dairy TMR Component

Figure 1. Component selection by 5 group-housed European starlings for dairy TMR with energy nugget (Nestle Purina, St. Louis, $\mathrm{MO}) . \mathrm{SFC}=$ steam-flaked corn; $\mathrm{DDG}=$ dried distillers grain. Error bars denote SE. $\mathrm{kg}$ of milk/d, total required net energy intake $\left(\mathbf{N E}_{\mathbf{I}}\right)$ was $31.5 \mathrm{Mcal} / \mathrm{d}$. Within the reference TMR the $\mathrm{NE}_{\mathrm{I}}$ supplied was $29.3 \mathrm{Mcal} / \mathrm{d}$, and within the starling consumed TMR the $\mathrm{NE}_{\text {I }}$ supplied was $27.7 \mathrm{Mcal} / \mathrm{d}$. The resulting energy balance for reference and starling controlled rations was -2.2 and $-3.9 \mathrm{Mcal} / \mathrm{d}$, respectively. Consequently, Holsteins fed the reference TMR were estimated to lose $1 \mathrm{BCS}$ in $161 \mathrm{~d}$ and experience daily weight change due to reserves of $-0.4 \mathrm{~kg} / \mathrm{d}$. Holsteins fed starling consumed TMR could potentially lose 1 condition score in $91 \mathrm{~d}$ and experience daily weight change due to reserves of $-0.8 \mathrm{~kg} / \mathrm{d}$.

\section{Pellet Size Analysis}

Pelleted feed was effective at deterring starlings from consuming food $\left(\mathrm{F}_{5,66}=316.88, P<0.001\right.$, Table 4$)$.

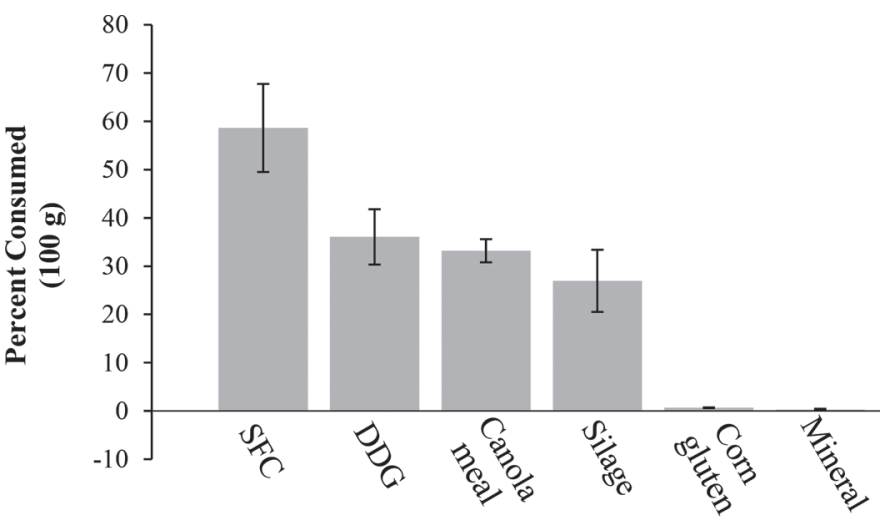

Dairy TMR Component

Figure 2. Component selection by 5 group-housed European starlings for dairy TMR excluding energy nugget (Nestle Purina, St. Louis, $\mathrm{MO}$ ). $\mathrm{SFC}=$ steam-flaked corn; $\mathrm{DDG}=$ dried distillers grain. Error bars denote $\mathrm{SE}$. 
Table 3. Output of NRC (2001), dairy production model for reference and rations exposed to starlings

\begin{tabular}{|c|c|c|}
\hline NRC model output & Reference TMR & Starling TMR ${ }^{1}$ \\
\hline $\mathrm{NE}_{\mathrm{I}}^{2}$ required $(\mathrm{Mcal} / \mathrm{d})$ & 31.5 & 31.5 \\
\hline $\mathrm{NE}_{\mathrm{I}}$ supplied (Mcal/d) & 29.3 & 27.7 \\
\hline $\mathrm{NE}_{\mathrm{I}}$ balance $(\mathrm{Mcal} / \mathrm{d})$ & -2.2 & -3.9 \\
\hline Days to lose $1 \mathrm{BCS}$ & 161 & 91 \\
\hline Weight change $(\mathrm{kg} / \mathrm{d})$ & -0.4 & -0.8 \\
\hline RDP required (g/d) & 1,778 & 1,674 \\
\hline RDP supplied (g/d) & 2,141 & 2,154 \\
\hline RDP balance (g/d) & 363 & 481 \\
\hline RUP required (g/d) & 2,016 & 2,134 \\
\hline RUP supplied (g/d) & 1,526 & 1,469 \\
\hline RUP balance $(\mathrm{g} / \mathrm{d})$ & -490 & -665 \\
\hline MP - bacterial (g/d) & 967 & 911 \\
\hline$M P-\operatorname{RUP}(\mathrm{g} / \mathrm{d})$ & 780 & 733 \\
\hline MP - endogenous $(\mathrm{g} / \mathrm{d})$ & 84 & 79 \\
\hline
\end{tabular}

${ }^{1}$ Changes to starling exposed TMR based upon a mass decrease of 0.14 $\mathrm{kg} /$ cow of Propel energy nugget (Nestle Purina, St. Louis, MO) and $0.75 \mathrm{~kg} /$ cow of steam-flaked corn.

${ }^{2} \mathrm{NE}_{\mathrm{I}}$ refers to net energy intake and it is measured in megacalories per day.

Starling consumption of 0.953 -cm (3/8-in) diameter pellets or larger inhibited starling consumption of feed. Pelleted feed of $0.553(7 / 32 \mathrm{in})$ and $0.396 \mathrm{~cm}(5 / 32$ in) in diameter did not deter starlings from consuming food relative to their pretreatment consumption rates $\left(\mathrm{F}_{1,22}=1.80, P<0.1934\right)$. Thus, pelleted feed of 0.953 $\mathrm{cm}$ in diameter or larger reduced starling consumption of feed by $\geq 79 \%$.

\section{DISCUSSION}

Commercial dairies formulate TMR primarily to maximize milk production. Our results suggest that large foraging flocks of starlings can alter the nutritional characteristics of TMR, and these changes may be large enough to reduce milk production in dairies based upon our NRC production model equations. Unfortunately dairies lack the tools necessary to measure these effects and take corrective actions. With precise estimates of site-specific bird damage (i.e., nutritional depletion and the corresponding changes in available net energy), producers could be better equipped to decide upon an appropriate course of action to mitigate losses caused by foraging flocks of birds.

Our component selection assessment suggests significant variability exists in the TMR components consumed by starlings. Additionally, it appears that the amount of feed consumed by starlings varies by food quality. When EN was available, the 5 group-housed starlings only ate $21.5 \mathrm{~g}$ of TMR/bird per day. When EN was absent, these same birds shifted feed selection to SFC and DDG and consumed $31.1 \mathrm{~g} /$ bird per day; this is a $45 \%$ increase in per-bird feed consumption. Unfortunately, the component assessment was not replicated and should be viewed with some caution. Regardless, this information will likely be important because the cost of lost feed will be heavily influenced by the amount of components consumed and the cost of those components. We suspect component selection will differ in dairies depending upon the ration offered. We recommend dairies experiencing bird damage work with their dairy nutritionists and extension agents to better gauge feed loss and identify least-cost rations to minimize economic losses to birds.

The nutrition data suggest that starlings are avoiding fibrous feed sources (i.e., hay, straw, and corn silage minus the kernels) and selecting food sources high in ME. This information may be enough for producers to make educated guesses as to what components birds will be consuming from their own TMR formulations. For example, high-energy components, such as EN, SFC, DDG, and corn chop from silage, are likely to be consumed by starlings. Some bakery and distillery products may attract starlings, and others may be bird resistant if they exist in sizes that inhibit starling consumption $(\geq 0.953 \mathrm{~cm}$ in diameter). Preventing starlings from obtaining the nutrients they need may force them to leave a dairy in favor of alternative feeding sites. Thus, the added time and cost of feeding milled or pelleted supplements may make economic sense when factored against the cost of lost feed and potential production losses.

Table 4. Assessment of pellet feed as a deterrent to starling consumption of livestock feed supplies

\begin{tabular}{|c|c|c|c|c|c|}
\hline Pellet diameter (cm) & Sample size (n) & Feed offered (g) & Feed $^{1}$ consumed $(\mathrm{g})$ & $95 \% \mathrm{CI}^{2}$ & $\begin{array}{l}\text { Bonferroni mean } \\
\text { difference }^{3}\end{array}$ \\
\hline 2.22 & 11 & 150 & 6.25 & $2.22-10.29$ & $\mathrm{~A}$ \\
\hline 1.91 & 11 & 150 & 6.08 & $2.05-10.12$ & $\mathrm{~A}$ \\
\hline 1.27 & 11 & 150 & 5.62 & $1.58-9.65$ & $\mathrm{~A}$ \\
\hline 0.95 & 11 & 150 & 16.82 & $12.78-20.85$ & $\mathrm{~B}$ \\
\hline 0.55 & 11 & 150 & 75.14 & $71.10-79.17$ & $\mathrm{C}$ \\
\hline 0.39 & 11 & 150 & 80.45 & $76.42-84.49$ & $\mathrm{C}$ \\
\hline
\end{tabular}

${ }^{1}$ Mean consumption/cage per treatment group. Each cage had 2 starlings.

${ }^{2} 95 \%$ confidence intervals for the mean consumption/cage.

${ }^{3}$ Different letters identify non-overlapping confidence intervals based upon Bonferroni-adjusted LSM estimates. 
The particle size analysis suggests dairies may be able to mitigate losses through the physical manipulations of TMR. Feeding cattle $\geq 1.27$-cm (1/2-in) diameter pellets was effective at preventing starling consumption in a Kansas feed yard (Depenbusch et al., 2011). Our data suggests particle sizes as small as $0.953 \mathrm{~cm}$ (3/8 in) in diameter will be effective at deterring bird feeding. Alternatively, starlings provided $0.476-\mathrm{cm}$ diameter pig pellets consumed the rations at a rate more than 8 times greater than granular hog meal (Twedt and Glahn, 1982). Our data suggests pellets of 0.553 $(7 / 32)$ and $0.396 \mathrm{~cm}(5 / 32 \mathrm{in})$ did not inhibit nutrient sourcing by starlings. The totality of this information is important, because feed consumption rates by starlings appear to be strongly influenced by feed form and size (Glahn et al., 1983). In other words, starlings may be excluding nutritious food options when the food matrix is of a size or shape that is difficult to consume (e.g., pelleted or ground feed). Therefore, we believe that combining high-energy components into $0.953-\mathrm{cm}$ diameter pellets may be a cost-effective and nonlethal strategy to reduce bird damage in dairies.

We recognize some limitations of the data presented in this manuscript. Because pest starlings may not nutritionally deplete all TMR consumed by cows daily, our results may overestimate the nutritional depletion caused by starlings at commercial dairies. Moreover, 5 starlings per $1 \mathrm{~kg}$ of TMR translates to starling numbers in excess of 100 birds per cow. This level of bird damage is equivalent to the highest levels of bird damage we have ever seen in the United States; approximately $\geq 100,000$ birds per 1,000 dairy cows (e.g., California, Kansas, Texas in 1980-2000; USDA Wildlife Services, personal communication). Most commercial dairies will likely not experience such severe nutritional offsets or production effects as those estimated herein.

It is also important to note that nutritional effects and predictive models were constructed using late-lactation dairy rations. These animals were being offered less feed and they had already begun to produce less milk relative to their peak performance. Therefore, we recommend that future analyses include nutritional effects to rations offered to milk cows at peak performance. Additionally, our production model output assumes that the density of pest birds does not change throughout winter. This may not be sufficiently accurate for predictive models, because starling feeding in dairies varies depending upon ambient temperature and local weather conditions (Linz et al., 2007; Carlson et al., 2012; Shwiff et al., 2012). Typically the worst starling damage occurs on very cold days following severe winter storms (Carlson et al., 2011, 2012). This is likely due to the fact that the caloric requirements of birds, on a daily basis, is climatically constrained
(Homan et al., 2013). Regardless of these shortcomings, our data demonstrates that we can measure the nutritional effects caused by depredating birds, and through these measurements dairy production models can be used to predict the production losses to dairies caused by bird depredation.

In conclusion, the data reported in this manuscript suggests that bird depredation of cattle feed by invasive European starlings causes nutritional depletion of dairy TMR, and these losses have the capacity to affect milk production. Additionally, we hypothesized that alternate components, less accessible to birds, may be supplemented in the TMR to repel birds and offset losses to animal performance and milk production. Bird-specific TMR could potentially be developed to maintain high levels of productivity using components and particle sizes less accessible or less desirable to pest birds. Additionally, site-specific data, similar to what we have produced in the current manuscript, could be used by dairies to help balance rations while accounting for bird damage. In other words, if we know the nutrient requirement of the offending bird species, we can predict losses, based on flock size, and modify feed formulations accordingly.

\section{REFERENCES}

Benjamini, Y., and Y. Hochberg. 1995. Controlling for false discovery rate: A practical and powerful approach to multiple testing. J. R. Stat. Soc. 57:289-300.

Bentz, T., S. Lapidge, D. Dall, and R. G. Sinclair. 2007. Managing starlings in Australia - Can DRC-1339 be the answer. Pages 361364 in Managing Vertebrate Invasive Species: Proceedings of an International Symposium. USDA/APHIS/WS, National Wildlife Research Center, Fort Collins, CO.

Besser, J. F., J. W. DeGrazio, and J. L. Guarino. 1968. Cost of wintering starlings and red-winged blackbirds at feedlots. J. Wildl. Manage. 32:179-180.

Carlson, J. C., J. W. Ellis, S. K. Tupper, A. B. Franklin, and G. M. Linz. 2012. The effect of European starlings and ambient air temperature on Salmonella enterica contamination within cattle feed bunks. Human-Wildlife Interactions 6:64-71.

Carlson, J. C., A. B. Franklin, D. R. Hyatt, S. E. Pettit, and G. M. Linz. 2011. The role of starlings in the spread of Salmonella within concentrated animal feeding operations. J. Appl. Ecol. 2:479-486.

Depenbusch, B. E., J. S. Drouillard, and C. D. Lee. 2011. Feed depredation by European starlings in a Kansas feedlot. Human-Wildlife Interactions 5:58-65.

Dolbeer, R. A., P. A. Wornecki, J. R. Strickley, and S. B. White. 1978. Agricultural impact of a winter population of blackbirds and starlings. Wilson Bull. 90:31-44.

Feare, C. J. 1984. The Starling. Oxford University Press, Oxford, UK.

Feare, C. J., P. Douville de Franssu, and S. J. Peris. 1992. The starling in Europe: Multiple approaches to a problem species. Page 83 in Proc. 15th Vertebr. Pest Conf. Sacramento, California. University of California, Davis

Feare, C. J., and K. P. Swannack. 1978. Starling damage and its prevention at an open-fronted calf yard. Anim. Prod. 26:259-265.

Glahn, J. F. and D. L. Otis. 1981. Approach for assessing feed loss damage by starlings at livestock feedlots. ASTM Special Technical Publication No. 752. American Society for Testing and Materials, Philadelphia, PA. 
Glahn, J. F., D. J. Twedt, and D. L. Otis. 1983. Estimating feed loss from starling use of livestock feed troughs. Wildl. Soc. Bull. $11: 366-372$.

Homan, J. H., R. S. Stahl, and G. M. Linz. 2013. Comparison of two models for estimating mortality from baitings with Compound DRC-1339 Concentrate avicide. Crop Prot. 45:71-75.

Lee, C. 1987. Results of a bird damage survey of Kansas feedlots. Page 29 in Proc. Great Plains Wildlife Damage Control Workshop, Univ. Nebraska, Lincoln. University of Nebraska, Lincoln.

LeJeune, J., H. J. Homan, G. M. Linz, and D. L. Pearl. 2008. Role of the European starling in the transmission of E. coli O157 on dairy farms. Page 31 in Proc. 23rd Vertebr. Pest Conf., San Diego, CA. University of California, Davis.

Linz, G. M., H. J. Homan, S. M. Gaukler, L. B. Penry, and W. J. Bleier. 2007. European starlings: A review of an invasive species with far-reaching impacts. Page 378-386 in Managing Vertebrate Invasive Species: Proceedings of an International Symposium. USDA/ APHIS/WS, National Wildlife Research Center, Fort Collins, CO.

NRC. 2001. Nutrient Requirements of Dairy Cattle, 7th ed. Natl. Acad. Press, Washington, DC.
Rollins, L. A., A. P. Woolnough, A. N. Wilton, R. G. Sinclair, and W. A. Sherwin. 2009. Invasive species can't cover their tracks: Using microsatellites to assist management of starling (Sturnus vulgaris) populations in Western Australia. Mol. Ecol. 18:1560-1573.

Shwiff, S. A., J. C. Carlson, H. Glass, J. Suckow, M. S. Lowney, K. M. Moxcey, B. Larson, and G. M. Linz. 2012. Producer survey of bird livestock interactions in commercial dairies. J. Dairy Sci. 95:6820-6829.

Twedt, D. J., and J. F. Glahn. 1982. Reducing starling depredation at livestock feeding operations through changes in management practices. Pages 159-163 in Proc. 10th Vertebr. Pest Conf., Monterey, CA. University of California, Davis.

USDA APHIS (Animal and Plant Health Inspection Service). 2011. Wildlife Services Policy Manual, Directive 2.505, Lethal Control of Animals.

Wright, E. N. 1973. Experiments to control starling damage at intensive animal husbandry units. Bull. OEPP 2:85-89. 